Forthcoming in Energy Economics.

\title{
ENERGY CONSUMPTION IN CHINA: PAST TRENDS AND FUTURE DIRECTIONS
}

\author{
Paul Crompton and Yanrui $\mathrm{Wu}^{*}$ \\ Economics Program \\ School of Economics and Commerce \\ University of Western Australia \\ 35 Stirling Highway \\ Crawley, WA, 6009 \\ AUSTRALIA \\ Phone : 610864882929 \\ Fax : 610864881016 \\ Email : Paul.Crompton@uwa.edu.au \\ Yanrui.Wu@uwa.edu.au
}

* The authors would like to thank Peter Summers for a copy of the Gauss program used in this paper. 


\begin{abstract}
In 2003 China's energy consumption amounted to 1678 million tonnes coal equivalent (MTCE), making China the world's second largest consumer behind only the United States. China is now also one of the largest oil importers in the world. With an economy which is expected to maintain a rate of growth of 7 to 8 per cent for decades, China's role in the world energy market becomes increasingly influential. This makes it important to predict China's future demand for energy. The objective of this paper is to apply the Bayesian vector autoregressive methodology to forecast China's energy consumption and to discuss potential implications. The results of this paper suggest that total energy consumption should increase to $2173 \mathrm{MtCE}$ in 2010, an annual growth rate of 3.8 per cent which is slightly slower than the average rate in the past decade. The slower growth reflects an expected slower economic growth and the decline in energy consumption due to structural changes in the Chinese economy.
\end{abstract}

Keywords: China, Energy consumption, Bayesian vector autoregression.

JEL classification numbers: Q41, C53. 


\section{Introduction}

With a population exceeding 1.3 billion and economic growth over the past two decades averaging around 8 per cent (following market reforms commencing in the late 1970s), China's demand for energy has surged to fuel its rapidly expanding industrial and commercial sectors as well as households experiencing rising living standards. Today, China is the second largest consumer of energy products in the world behind the United States, consuming annually around 1.7 billion tonnes coal equivalent of energy. In 2003, China accounted for 31 per cent of world coal consumption, 7.6 per cent of oil consumption, 10.7 per cent of hydro-electricity consumption and 1.2 per cent of gas consumption. Furthermore, China's global consumption share of all four energy fuels has increased sharply in recent decades. For example, in 1985, China's global shares were 20.7 per cent for coal, 3.2 per cent for oil, 0.7 per cent for gas and 4.6 per cent for hydro-electricity. ${ }^{1}$ Indeed growth in energy consumption has been so strong since the early 1980s that it has outpaced growth in domestic energy supply leading to a substantial expansion in China's energy imports, mainly oil.

The heavy reliance on coal in China is due to abundant domestic stocks of coal, the tight control of commodity prices and resultant underpricing of coal products during the central planning era and a lack of environmental awareness for many decades. Today, following two decades of rapid economic growth and rising demand for energy products, China's citizens are becoming more environmentally aware. As a result, Chinese policy makers have begun acknowledging the need to resort to cleaner sources of energy, particularly natural gas and hydro-electricity. Continued movement in this direction should see the share of coal in China's total energy consumption decline further, with the share of oil, gas and hydro-electricity increasing substantially.

Continued growth in energy consumption and changes in the composition of energy use away from coal raises important issues for the security of China's energy supply. In 2003, China had 114.5 billion tonnes of coal reserves, some 11.6 per cent of the world's proven recoverable reserves, suggesting a reserves to production ratio of 69

\footnotetext{
${ }^{1}$ Calculated from BP Statistical Review of World Energy (2004).
} 
years. $^{2}$ The majority of these reserves are steaming coal suitable for electricity generation. The supply of alternate fuels however, is less secure. In 2003, China's imports of oil reached 128.3 million tonnes, or around 46 per cent of domestic oil consumption, following growing energy demand/supply imbalances as domestic supply struggled to keep pace with demand. Despite a heavy reliance on imports, China is the world's fifth largest oil producer and is currently searching for new reserves in China's remote Tarin Basin in the country's north-west and offshore in the South China Sea. Natural gas reserves in China are plentiful, yet supply is currently restricted by inadequate gas distribution infrastructure. Furthermore, gas prices in China are set by the government at levels that makes it difficult for gas to compete with coal on a cost basis. The final major alternate energy source is hydroelectricity, of which China has the world's largest potential, estimated at $675 \mathrm{GW}$ (gigawatts), yet only $290 \mathrm{GW}$ are commercially viable, with less than one quarter currently exploited (International Energy Agency 1999).

Forecasts of growth in China's energy consumption are important for two reasons. First, continuation of the strong growth in energy consumption in recent decades will see underlying demand and supply imbalances in China increasingly affect global energy markets, particularly oil and natural gas. Second, long term forecasts are required to assess the need for future trade and investment strategies to ensure the security of China's energy supply. This paper uses macroeconomic Bayesian vector autoregression models (BVAR) to forecast the consumption of coal, oil, natural gas and hydro-electricity in China to 2010. The results suggest that continued strong growth in consumption can be expected to at least 2010, albeit at a slower rate than prior to 1997. Total energy consumption is forecast to rise from $1678 \mathrm{MtCE}$ (million tonnes coal equivalent) in 2003 to $2173 \mathrm{MtCE}$ in 2010. The composition of energy consumption is also forecast to change in China. Oil, gas and hydro-electricity are expected to take on larger market shares as growth in coal consumption slows over time.

The following section presents a preliminary analysis of energy consumption in China. This is followed by a review of previous literature in the field. Subsequently,

${ }^{2}$ BP Statistical Review of World Energy (2004). 
the modelling framework and empirical results are presented. The final section concludes the paper.

\section{ENERGY CONSUMPTION IN CHINA}

Total energy consumption (coal, oil, gas, hydro-electricity) in China increased from $54 \mathrm{MtCE}$ in 1953 to $1389 \mathrm{MtCE}$ in 1996, an average annual growth rate of 8.9 per cent (see Figure 1). Despite the continuation of strong growth in GDP, energy consumption fell unexpectedly in 1997 to $1377 \mathrm{MtCE}$, and by 1999 had fallen to 1301 MtCE, sparking fears of a permanent structural shift in Chinese energy consumption. By 2001, however, consumption in China had recovered to $1349 \mathrm{MtCE}$ and by 2003 had risen further to $1678 \mathrm{MtCE}$. Of this, coal consumption accounted for 67 per cent of total consumption. Oil was the next most important energy source, accounting for 23 per cent, while natural gas and hydro-electricity accounted for 3 and 7 per cent respectively.

China's energy consumption since 1953 has several distinct characteristics. First, growth in energy consumption has been accompanied by a dramatic decline in energy intensity of use (ie. energy consumption per unit of GDP) over the last two decades (see Figure 2). This change is even more obvious in an international context. When China initiated its economic reform programme in the late 1970s, China's energy intensity was double that of the US and triple that of Japan (see Figure 3). By 1999, China's energy intensity had fallen to levels more comparable to that of the US and Japan. Technical and structural changes have been identified as the main factors that caused the fall in energy intensity in China. ${ }^{3}$ It can also be argued that the fall in end-use energy intensity is partially the result of an improvement in energy efficiency and development of new materials (Galli 1998, Sinton and Fridley 2000). These explanations have also been supported by a recent study involving firm-level data (Fisher-Vanden et al. 2004).

\footnotetext{
${ }^{3}$ See, for example, Kambara (1992), Huang (1993), Lin and Polenske (1995), Garbaccio et. al (1999) and Fisher-Vanden et al. (2004).
} 
FIGURE 1

Total Energy Consumption in China, 1953-2003

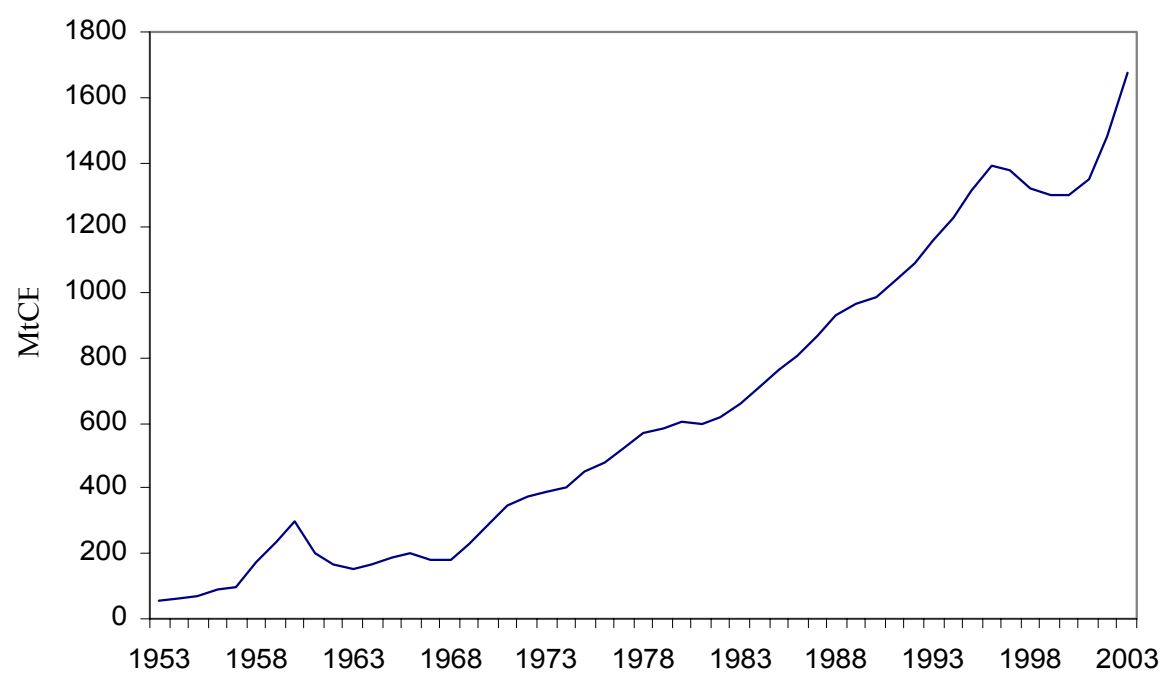

Source: State Statistical Bureau (various issues).

FIGURE 2

Energy Intensity of Use in China, 1953-2003

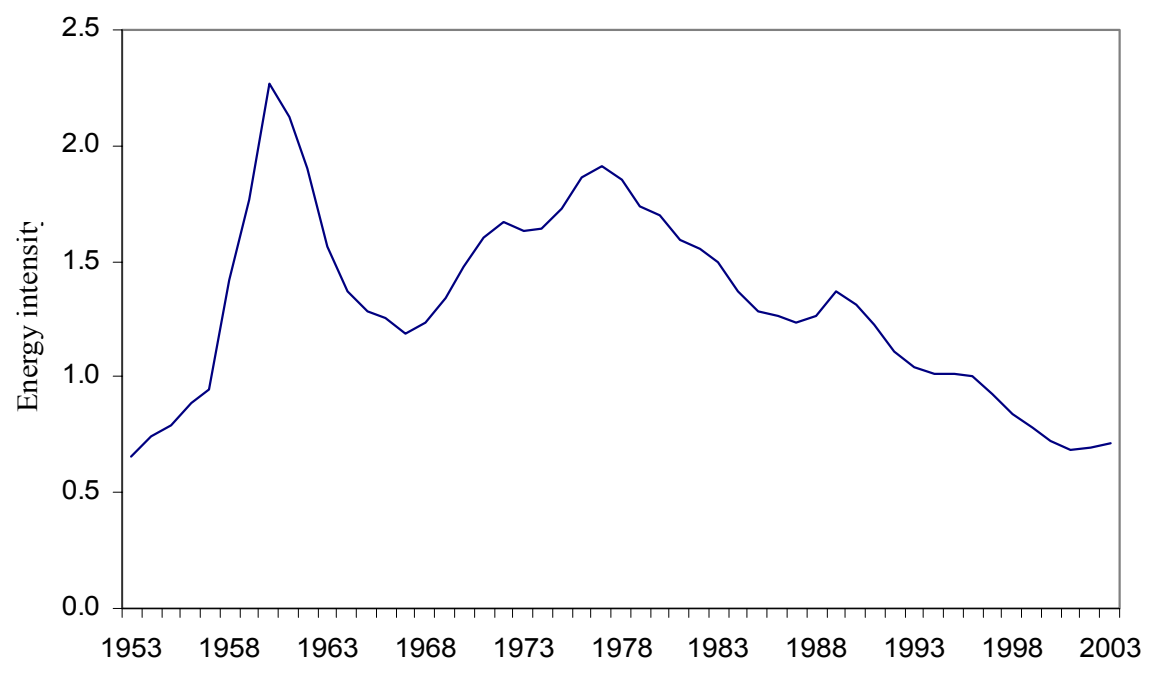

Source: Calculated from State Statistical Bureau (various issues).

Note: Intensity of use is expressed in tonnes coal equivalent per 1000 yuan measured at 1953 constant prices. 


\section{FIGURE 3}

\section{Energy Intensity of Use in Selected Countries, 1971-1999.}

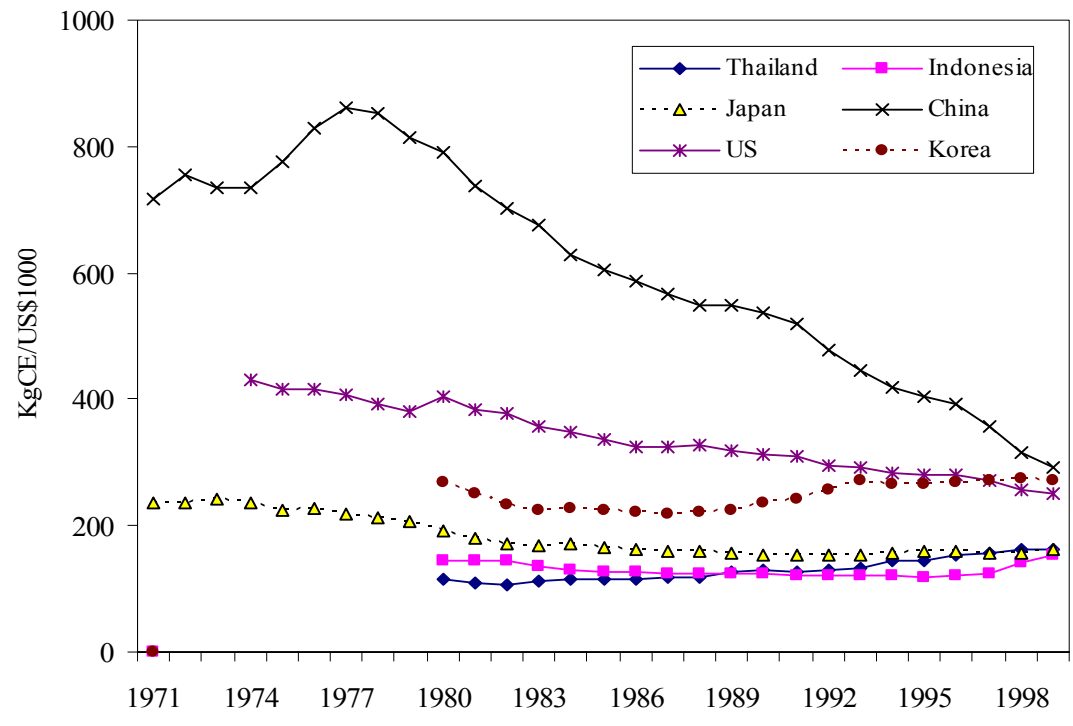

Source: Calculated from World Bank (2002) and APEC (2002).

Second, the composition of energy consumption in China is unbalanced in comparison with other countries (see Table 1). This is highlighted by the large domestic market share of coal in China, although its dominance has declined in recent years. Furthermore, the role of natural gas is trivial. This situation has imposed a high cost on the economy in terms of environmental damage associated with excessive use of coal. As a result, the energy industry and policy makers are under tremendous pressure to change the structure of energy consumption and shift from coal to cleaner products such as natural gas and hydroelectricity.

Third, although China's energy consumption is large in absolute terms, energy consumption per capita of about 0.5 tonne oil equivalent (TOE) in 2001 is very small relative to that in the developed economies, eg. 5.4 TOE in the US, 3.0 TOE in Germany and 2.7 TOE in Japan during the same period. ${ }^{4}$ This difference implies great growth potential in energy demand in China. ${ }^{4}$ Calculated using statistics from China Energy Statistical Yearbook 2000-2002 which includes a
section reporting international energy statistics. 
TABLE 1

Composition of Energy Consumption in Selected Countries (percentage shares)

\begin{tabular}{lcrrrrrr}
\hline & 2003 & & & \multicolumn{1}{l}{1996} \\
& China & China & US & Japan & India & Russia Korea \\
& & & & & & & \\
\hline & 67.1 & 74.7 & 24.2 & 17.6 & 56.9 & 19.7 & 19.2 \\
Coal & 22.7 & 18.0 & 39.1 & 53.8 & 31.9 & 21.1 & 61.6 \\
Oil & 2.8 & 1.8 & 26.7 & 11.9 & 7.9 & 52.4 & 7.4 \\
Natural gas & 7.4 & 5.5 & 10.0 & 16.7 & 3.3 & 6.8 & 11.8 \\
Other & & & & & & & \\
\hline
\end{tabular}

Source: Keii (2000) and State Statistical Bureau (2004).

TABLE 2

Energy Consumption per capita, 2002

\begin{tabular}{|c|c|c|c|c|c|}
\hline & $\begin{array}{l}\text { Coal } \\
(\mathrm{kg})\end{array}$ & $\begin{array}{l}\text { Oil } \\
(\mathrm{kg})\end{array}$ & $\begin{array}{l}\text { Gas } \\
(\mathrm{cm})\end{array}$ & $\begin{array}{l}\text { Electricity } \\
\text { (kwh) }\end{array}$ & $\begin{array}{l}\text { Total } \\
\text { (kgce) }\end{array}$ \\
\hline & \multicolumn{5}{|c|}{ Developed provinces } \\
\hline Beijing & 1779 & 526 & 148 & 3064 & 3164 \\
\hline Tianjin & 2909 & 671 & 64 & 2790 & 3001 \\
\hline Shanghai & 2883 & 877 & 27 & 3974 & 3766 \\
\hline Jiangsu & 1309 & 191 & n.a. & 1686 & 1302 \\
\hline Zhejiang & 1295 & 267 & n.a. & 2186 & 1589 \\
\hline Shandong & 1425 & 179 & n.a. & 1354 & 1216 \\
\hline Fujian & 782 & 96 & n.a. & 1436 & 1007 \\
\hline \multirow[t]{2}{*}{ Guangdong } & 846 & 250 & n.a. & 2148 & 1445 \\
\hline & \multicolumn{5}{|c|}{ Developing provinces } \\
\hline Anhui & 1054 & 49 & n.a. & 615 & 839 \\
\hline Guangxi & 442 & 15 & n.a. & 740 & 618 \\
\hline Guizhou & 1355 & n.a. & 14 & 1281 & 1165 \\
\hline Yunnan & 774 & n.a. & 12 & 908 & 909 \\
\hline Shaanxi & 939 & 192 & 38 & 1018 & 1011 \\
\hline
\end{tabular}

Notes: $\mathrm{kg}$ (kilograms); cm (cubic meters); kwh (kilowatt hours) and kgce (kilograms coal equivalent). Sources: State Statistical Bureau (2003) and China Energy Statistical Yearbook 2000-2002.

Fourth, energy consumption in China is highly unbalanced between the rural and urban sectors as well as across the Chinese provinces. In 2000, for example, urban energy consumption of 1.38 TCE per capita was much greater than rural consumption of 0.83 TCE. $^{5}$ The disparity in per capita energy consumption across China's provinces is highlighted in Table 2. For example, electricity consumption in

\footnotetext{
${ }^{5}$ Calculated using population and energy consumption data from State Statistical Bureau (2002) and Editorial Board (2001).
} 
Shanghai province is between three and six times higher than in China's developing provinces. Provincial and rural-urban energy consumption patterns in China however, can be expected to change in response to changes in income distribution patterns. Over time, as regional income disparity narrows, rural consumers will catch up with their urban counterparts and poor areas with rich regions. This catching-up effect will also affect China's overall energy demand in the future.

Finally, China's energy demand has also been influenced by the growth in demand for energy-intensive products such as automobiles and air-conditioners. The number of registered motor vehicles in China has increased from 6.2 million in 1990 to 36.0 million in 2003 (State Statistical Bureau 2004). The ownership of air conditioners in China's urban households has increased from 11.6 per cent in 1990 to 61.8 per cent in 2003 (State Statistical Bureau, various issues and 2004).

These features of China's energy consumption imply that strong growth in energy demand will continue in the future. This growth is likely to be sustained due to the expected continued expansion in the Chinese economy, with an average rate of economic growth in the coming decade projected to be about 7 per cent (World Bank 1997). Currently, China is heading into its next cycle of high growth following the downturn in the late 1990s.

China, with a share of 12.1 per cent of the world's total energy consumption, is already a significant player in the global energy market ${ }^{6}$. China's imports of crude oil of 91.1 million tons in 2003 accounted for about 35 per cent of the country's total oil supply, that is, production plus imports. ${ }^{7}$ In 2002 , China signed a 25 -year contract to import annually 3 million tons of liquefied natural gas from Australia. Further growth in China's domestic energy consumption will have important implications for the world energy industry. This makes forecasting energy consumption in China an important contribution to the field.

\footnotetext{
${ }^{6}$ Computed using statistics from the International Energy Agency (www.iea.org) and from the State Statistical Bureau (2003).

${ }^{7}$ According to the State Statistical Bureau (2004).
} 


\section{PREVIOUS STUDIES}

Several recent studies have presented forecasts of energy consumption in China. The differences in the forecasts presented in these studies are attributable to differences in the data sets and forecasting techniques used. According to Shi and Zhao (1999), China's total energy consumption is projected to increase from about $920 \mathrm{MtOE}$ (million tonnes oil equivalent) in 2001 to $1,150 \mathrm{MtOE}$ in 2005 and 1,550 MtOE in 2015 The implied average annual rate of growth is 5.1 per cent during 2001-2005 and 3.1 per cent during 2005-2015. Those rates will vary across the regions as well as the sectors. The coastal regions will continue to be the leading energy growth regions. Transportation and residential sectors will likely be the sectors contributing to China's increased energy consumption in the future.

TABLE 3

China's Energy Projections

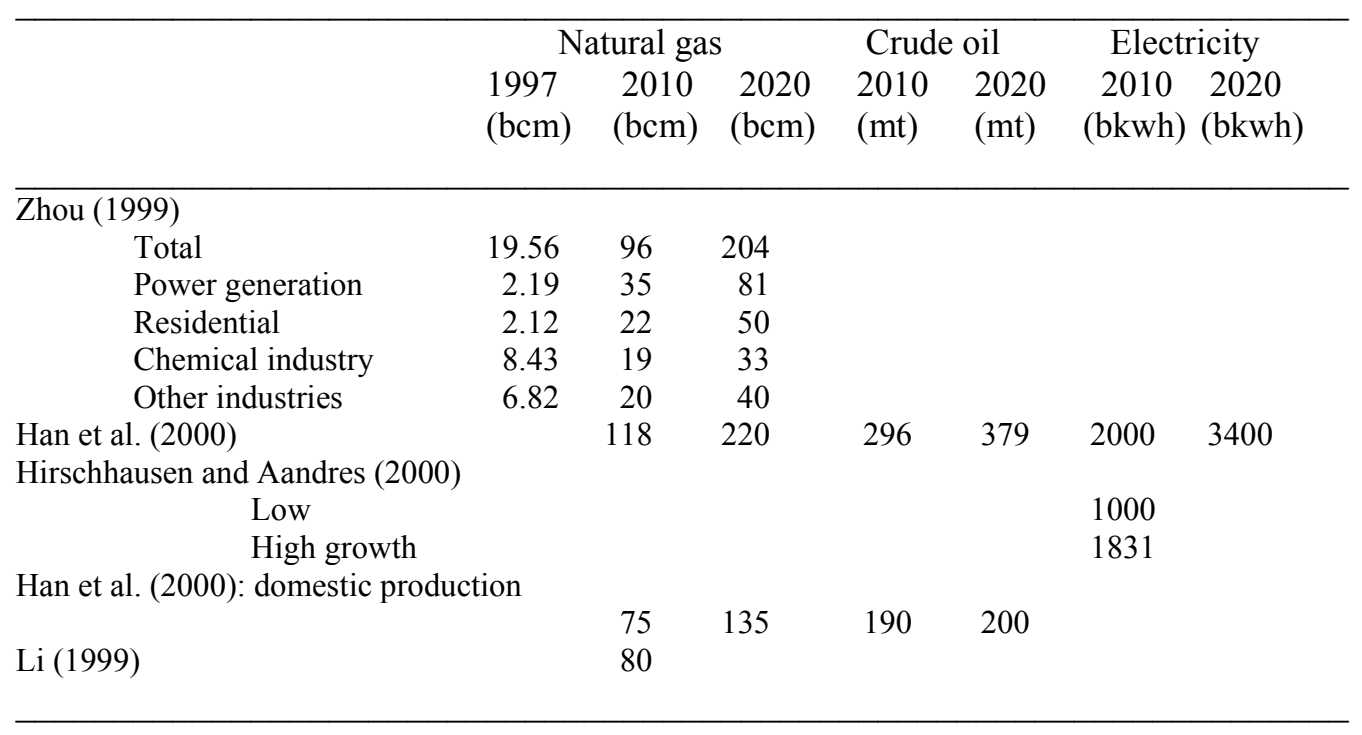

Note: bcm (billion cubic metres); mt (million tonnes); bkwh (billion kilowatt-hours).

China's rising energy consumption will boost domestic demand for coal, petroleum products, electricity and natural gas. Due to the change in energy structure, growth will be biased towards cleaner energy such as natural gas. The demand for coal will continue to grow modestly as coal is still the cheapest fuel in China. The International Energy Agency projects that coal demand will increase annually at 3.1 
per cent in the next two decades (IEA 1999). Keii (2000) derives a more modest annual rate ( 2 per cent) of growth for coal consumption in the coming decade. According to Keii's projection, China's demand for coal will reach 1.3 billion tons in 2010. However, the share of coal as a primary energy over total energy consumption will decline over time. By 2010, coal will account for about 65 per cent of China's primary energy (Keii 2000).

China's demand for natural gas is projected to be around 100 billion cubic meters (bcm) in 2010 and $200 \mathrm{bcm}$ in 2020 (Table 3). The implied annual rate of growth in the first two decades of the $21^{\text {st }}$ century is about 9 per cent according to Han et al. (2000) and 11 per cent according to Zhou (1999). In addition, according to both sources, growth in demand will be much greater in the first ten years.

The projected growth in the consumption of oil and electricity is modest. For example, Han et al. (2000) estimated an annual rate of growth of 4 per cent for crude oil consumption and 5 per cent for electricity demand during 2000-2020. Obviously, the fastest growth area is natural gas. The two largest users of natural gas will be the residential and power generation sectors. Demand in these sectors is projected to grow at a rate greater than 20 per cent during the period 2000-2010 (Table 3). This growth can only become possible with overseas supplies. Han et al. (2000) estimated that China's imports of natural gas would reach $35 \mathrm{bcm}$ in 2010 and $75 \mathrm{bcm}$ in 2020 . Given the projected rate of growth and the stagnation of domestic production of oil, China will also have to reply on offshore sources to meet the demand. Han et al. (2000) predicted that China oil imports would increase from 57 million tons in 1999 to 106 million tons in 2010 and 180 million tons in 2020.

\section{A BAYESIAN VAR MODEL OF ENERGY CONSUMPTION}

Various approaches to forecasting have been used in the literature, including cointegration and error-correction models (Chan and Lee 1996) and demand equations (Hirschhausen and Andres 2000). As expected, the forecasts of Chinese energy consumption results vary considerably. In this study, we propose an alternative approach that uses Bayesian vector autoregression models and key macroeconomic variables to forecast energy consumption in China to 2010. 
A unrestricted vector autoregression model (UVAR) containing $n$ time series variables and a lag length of $k$ has the general form

$$
y_{t}=A_{0}+A_{1} y_{t-1}+A_{2} y_{t-2}+\ldots .+A_{k} y_{t-k}+u_{t}
$$

where $y_{t}=\left(y_{1}, y_{2}, \ldots, y_{n}\right)^{\prime}$ is an $(n \times 1)$ vector of endogenous variables, $A_{0}$ is an $(n$ $\times 1)$ vector of intercept terms, $A_{i}, i>0$, are $(n \times n)$ coefficient matrices and $u_{t}$ is an $(n$ $\times 1)$ vector of white noise residuals. The vector $A_{0}$ contains $n$ intercept terms and each matrix $A_{i}$ contains $n^{2}$ coefficients, hence $n+k n^{2}$ coefficients must be estimated, which increases exponentially with the number of variables in the system. The $n$ variables included in the system are all assumed to be endogenous. ${ }^{8}$ A major problem in the estimation of VAR models when $k$ is large is overparameterization, where too many coefficients must be estimated relative to sample size. Estimation of the system will typically yield numerous insignificant coefficients that can be properly excluded from the model. ${ }^{9}$ The imposition of zero restrictions on such coefficients however, implies a level of certainty regarding the validity of the exclusion restrictions that is often not held by the modeller.

An alternate approach has been offered by the Bayesian vector autoregression (BVAR) methodology of Litterman (1980, 1986), Doan, Litterman, and Sims (1984), Sims (1992) and Sims and Zha (1998). A BVAR model avoids the rigid inclusion/exclusion restrictions of VAR models by allowing the modeller to include many coefficients while simultaneously controlling the extent to which they can be influenced by the data. This reduces the extent to which spurious correlations are captured by the model, thereby improving forecasting performance. The BVAR approach modifies the OLS estimates of equation (1) by treating all coefficients as random variables around their Bayesian prior mean, such that the modeller has the

\footnotetext{
${ }^{8}$ This is a particularly useful assumption when the underlying structure of the system is either unknown, or highly complex in that specific statistical relationships between variables are difficult to isolate.

${ }^{9}$ A related point is that the large number of coefficients that are included in unrestricted VAR models tends to fit the data unrealistically well, while performing poorly in out-of-sample forecasting due to the effects of spurious correlations in the data set. Zha (1998) also points out that overfitting of the data can distort the long run relationships between variables in the model and inflate coefficient values on distant lags due to low degrees of freedom.
} 
flexibility to impose these priors, to varying degrees, on the coefficient estimates. The system of priors most commonly used in the specification of BVAR models is the Minnesota prior, which has its origins at the University of Minnesota and the Federal Reserve Bank of Minneapolis. To illustrate, we express the BVAR as

$$
y_{t}=B_{0}+B_{1} y_{t-1}+B_{2} y_{t-2}+\ldots .+B_{k} y_{t-k}+v_{t}
$$

where $B_{i}, i>0$, are $(n \times n)$ coefficient matrices, each element of which now has a Bayesian prior. Each element in the lagged coefficient matrix $B_{i}$ is assumed to be an independent, normally distributed random variable, with the prior mean on the first lag matrix, $B_{1}$, equal to an identity matrix and the prior mean on matrices $B_{i}, i>1$, equal to zero. ${ }^{10}$ While this random walk specification may describe well many macroeconomic variables, there is no need to impose the restriction exactly on the BVAR. Rather, the parameters in the system are estimated such that the priors are overridden where significant statistical evidence to the contrary exists.

Each $B_{i}, i>0$, also requires a corresponding matrix of variances, $V_{i}$, which individually control how far the estimated coefficients are permitted to deviate from their specified prior. The $p q$-th element of $V_{i}, i>0$, is $\lambda_{1} \sigma_{p} / i^{\lambda 3}$ for $p=q$, and $\lambda_{1} \lambda_{2} \sigma_{p} / i^{\lambda 3} \sigma_{q}$ for $p \neq q$. The parameter $\lambda_{1}$ is the prior variance on the diagonal elements in $B_{1}$, the lagged values of the dependent variable in each equation. Doan (1992) suggests arbitrarily setting this equal to one. The parameter $\lambda_{2}$ is the prior variance on the off-diagonal elements in $B_{1}$ and controls the magnitude of cross equation effects. Lowering $\lambda_{2}$ towards zero will force the estimated parameters on cross lags towards their prior of zero. The parameter $\lambda_{3}$ controls the decay rate of the variances as $k$ increases. This increasingly forces the estimated coefficients, as $k$ increases, towards the prior mean of zero, suggesting that observations further into the past are less likely to be useful in forecasting than more recent observations. If $\lambda_{3}$ is set to one, the rate of decay will be harmonic. The ratio $\sigma_{p} / \sigma_{q}$ adjusts the prior variances for differences in the units of measurement of the different variables. The

\footnotetext{
${ }^{10}$ This prior specification is also known as the unit root prior since, if the restrictions were imposed exactly, it would treat all $n$ variables in the system as random walk AR(1) processes, possibly with drift. The imposition of priors of zero on the coefficients in $B_{0}$ is standard for this specification.
} 
value of $\sigma_{p}$, for example, is typically set equal to the error variance of an OLS regression of the $p$-th equation on $k$ own lags.

One important modification of the Minnesota prior reflects the common practice of estimating BVAR models in first differences when the variables contain unit roots in levels. To illustrate, we write the BVAR model in first differences as

$$
\Delta y_{t}=\Gamma_{0}+\Gamma_{1} \Delta y_{t-1}+\Gamma_{2} \Delta y_{t-2}+\ldots .+\Gamma_{k} \Delta y_{t-k}+\varepsilon_{t}
$$

Doan, Litterman, and Sims (1984) suggest the use of a sum of coefficients prior which restricts the sum of the coefficients on the lagged values of the dependent variable in each equation equal to one, while the sums of coefficients on other variables sum to zero. Using the notation of Robertson and Tallman (1999), this constraint can written as $\sum_{i=1}^{k} \Gamma_{i}=I$, where $I$ is an $(n \times n)$ identity matrix. Implementation of this prior involves adding $n$ dummy observations to the start of the data set, one for each equation. For $n=2$, the dummy observations for the dependent variable in the first equation would be $\left(\mu_{5} \bar{y}_{1}^{0}, 0\right)^{\prime}$, and $\left(0, \mu_{5} \bar{y}_{2}^{0}\right)^{\prime}$ for the second equation, where $\bar{y}_{i}^{0}$ is the mean of the $k$ presample values of $y_{i}$. The parameter $\mu_{5}$ is the weight attached to the dummy observations such that as $\mu_{5} \rightarrow \infty$, the estimated coefficients in $\Gamma_{i}$ will be forced towards the sum of coefficients restriction. The corresponding dummy observations for the dependent variables with $k=2$ are

$$
\left(\begin{array}{ccccc}
0 & \mu_{5} \bar{y}_{1}^{0} & 0 & \mu_{5} \bar{y}_{1}^{0} & 0 \\
0 & 0 & \mu_{5} \bar{y}_{2}^{0} & 0 & \mu_{5} \bar{y}_{2}^{0}
\end{array}\right)
$$

where the first column of the matrix corresponds to the dummy observations for the intercept term. ${ }^{11}$ A second modification of the Minnesota prior, introduced by Sims (1992), allows for the possibility of cointegration between variables in the BVAR. Implementation requires the use of an additional dummy observation. For $n=2, k=2$, this observation would take the form $\mu_{6} \bar{y}_{i}^{0}$ for the dependent variables in each equation. The corresponding dummy observation for the independent variables is

\footnotetext{
${ }^{11}$ Note that both equations have an identical set of regressors.
} 
$\left(\mu_{6} \mu_{6} \bar{y}_{1}^{0} \mu_{6} \bar{y}_{2}^{0} \mu_{6} \bar{y}_{1}^{0} \quad \mu_{6} \bar{y}_{2}^{0}\right)$, where $\mu_{6}$ is the weight attached to the dummy observation. As $\mu_{6} \rightarrow \infty$, a single cointegrating vector, formed by a linear combination of the $n$ variables, is increasingly permitted to enter the model. ${ }^{12}$

Estimation of the BVAR model requires selection of values of the parameters $\lambda_{1}, \lambda_{2}$, $\lambda_{3}, \mu_{5}, \mu_{6}$. The selection procedure for these parameters is based upon a search process that minimises in-sample forecast errors. A full description of this process and parameter values are available from the authors upon request.

\section{ENERGY CONSUMPTION FORECASTS}

The forecasts of energy consumption presented in this section are estimated using Bayesian VAR models with unit root and cointegration restrictions imposed. Separate models are estimated for coal, oil, gas and hydro-electricity consumption over the sample period 1956 to 2003. The variables included in each model are energy consumption, real fuel price (expect for gas and hydro-electricity where prices were unavailable), real gross domestic product and population. The inclusion of GDP in the system is intended to capture the derived nature of energy consumption in domestic production, while the population variable captures the effects of residential energy demand. Actual values of energy consumption to 2003 and forecast values from 2004 onwards for the four fuel commodities are present in Table 4. For coal and oil, forecasts of energy consumption include the effects of a continuation of recent increases in the price of these fuels in China over the forecast period. This is consistent with continued reforms in China's energy sector which are expected to result in further price increases.

The forecasts in Table 4 suggest that total energy consumption will grow at an annual average rate of 3.8 per cent over the forecast period 2004 to 2010 . This is significantly lower than energy consumption growth from 1980 to the downturn in consumption in 1996 which averaged 5.4 per cent. Growth in the consumption of natural gas is forecast to be the highest of the energy fuels at an annual average rate

\footnotetext{
12 See Summers (2001) for a more detailed overview of the incorporation of the unit root and
} cointegration dummy observations into the BVAR framework. 
of 6.6 per cent. This compares with forecast annual growth rates of 3.7 per cent for hydroelectricity, 4.5 per cent for oil and 3.3 per cent for coal. Under these forecasts, the strong growth in the demand for natural gas will increase its share in total consumption, from 2.8 per cent in 2003 to 3.4 per cent in 2010. The share of hydroelectricity is forecast to remain constant at around 7.4 per cent. Slower growth in the demand for coal however, will see its share fall from 67 per cent to 65.4 per cent over the forecast period.

TABLE 4

Forecasts of Primary Energy Consumption

\begin{tabular}{cccccc}
\hline & & & & & \\
1990 & 752.1 & 163.8 & 20.7 & 50.3 & 987.0 \\
1991 & 789.8 & 177.5 & 20.8 & 49.8 & 1037.8 \\
1992 & 826.4 & 191.0 & 20.7 & 53.5 & 1091.7 \\
1993 & 866.5 & 211.1 & 22.0 & 60.3 & 1159.9 \\
1994 & 920.5 & 213.6 & 23.3 & 70.0 & 1227.4 \\
1995 & 978.6 & 229.6 & 23.6 & 80.0 & 1311.8 \\
1996 & 1037.9 & 250.1 & 25.0 & 76.4 & 1389.5 \\
1997 & 985.3 & 281.1 & 23.4 & 85.4 & 1378.0 \\
1998 & 920.2 & 284.3 & 29.1 & 88.6 & 1322.1 \\
1999 & 884.8 & 301.9 & 28.6 & 85.9 & 1301.2 \\
2000 & 861.3 & 320.5 & 32.6 & 88.6 & 1303.0 \\
2001 & 881.0 & 327.8 & 36.4 & 103.9 & 1349.1 \\
2002 & 972.3 & 355.7 & 38.5 & 115.6 & 1482.2 \\
2003 & 1125.9 & 380.9 & 47.0 & 124.2 & 1678.0 \\
2004 & 1176.8 & 391.0 & 50.5 & 128.8 & 1747.0 \\
2005 & 1215.9 & 402.9 & 54.1 & 133.4 & 1806.3 \\
2006 & 1245.1 & 417.5 & 57.8 & 138.2 & 1858.8 \\
2007 & 1274.1 & 435.4 & 61.6 & 143.2 & 1914.3 \\
2008 & 1311.1 & 457.6 & 65.5 & 148.4 & 1982.6 \\
2009 & 1359.7 & 485.4 & 69.4 & 154.0 & 2068.5 \\
2010 & 1421.1 & 519.5 & 73.3 & 159.7 & 2173.5 \\
& & & & & \\
\hline
\end{tabular}

Note: All figures are expressed as millions tonnes coal equivalent.

The forecast slowdown in energy consumption growth from 2004 to 2010 may be due to two reasons. First, during 1979 to 1998, China's economy had been growing at an average rate of 9.8 per cent annually (State Statistical Bureau 2003). However, since 1998, the country's economy has been growing at an average rate of 7 to 8 per cent, that is, about 2 percentage points lower than that in the previous period. The 
consensus view is that the Chinese economy will maintain its current growth momentum in the coming decade (International Monetary Fund 2003). Second, Figure 3 suggests that energy efficiency in China has increased dramatically since the late 1970s, leading to substantial reductions in energy intensity. There is however, still scope for further improvement through continued improvements in microeconomic efficiency and the adoption of new energy-saving technology.

The forecasts of energy consumption reported in Table 4 have several important implications for China. First, though its market share is declining, coal will continue to be the major source of energy for China, accounting for about 65 per cent of primary energy consumption by 2010. This figure is still extremely high in comparison with other countries (see Table 1). The overwhelming reliance on coal is expected to continue to present tremendous environmental challenges to China as well as the rest of the world. Second, in the last five years, China's oil inputs amounted to about one-third to a half of the country's total oil consumption. If this ratio is maintained, China's oil imports will be around 120-182 million tonnes by $2010 .{ }^{13}$ Thus, China oil imports could be twice as much as the 2003 level (91.1 mts). This would be challenging to both China and the rest of the world.

\section{CONCLUSION}

The forecasts presented in this paper suggest that significant growth in energy demand can be expected in China until at least 2010. Over the forecast period 2004 to 2010 , energy demand is forecast to rise at an annual average rate of 3.8 per cent, which is slightly lower than the growth rate in the last two decades. The forecast slower growth in energy consumption is consistent with the anticipated, relatively modest rate (7-8\% per annum) of economic growth in China in the coming decades. In addition, the slower growth in energy consumption also reflects the fact that there will be further structural changes in the Chinese economy and that subsequently some energy-intensive sectors in the economy are expected to decline. Concomitant with the slower growth in energy demand will be a continuation of the change in market shares with oil, natural gas and hydro-electricity becoming increasingly

\footnotetext{
${ }^{13}$ Estimated using the forecast figure in Table 4.
} 
important energy sources at the expense of coal, reflecting government policies towards the use of cleaner energy in China. 


\section{REFERENCES}

APEC (2002), ‘APEC Energy Statistics 2000’, Asia Pacific Economic Cooperation.

BP Statistical Review of World Energy (2004), www.bp.com/centres/energy/index.asp

Chan, H and Lee, S. (1996), 'Forecasting the demand for energy in China', Energy Journal, 17(1), 19-30.

China Energy Statistical Yearbook 2000-2002, compiled by Department of Industry and Transport Statistics, National Bureau of Statistics, and Energy Bureau, National Development and Reform Commission, People's Republic of China, Beijing: China Statistics Press.

Doan, T, Litterman, R.B. and Sims, C.A. (1984), 'Forecasting and conditional projection using realistic prior distributions', Econometric Reviews, 3, 1-100.

Editorial Board (2001), China's Energy Development Report 2001, Beijing: China Quantitative Publishing Press.

Fisher-Vanden, K., Jefferson, G.H., H. Liu and Q. Tao (2004), 'What is driving China's decline in energy intensity', Resource and Energy Economics, 26, 77-97.

Galli, R (1998), 'The relationship between energy intensity and income levels: forecasting long term energy demand in Asian emerging countries', The Energy Journal, 19(4), 85-105.

Garbaccio, R, Ho, M and Jorgenson, D (1999), 'Why has the energy-output ratio fallen in China?', Energy Journal, 20(3), 63-91.

Han, W, Liu, X and Zhu, X (2000), 'Analysis on China's supply of and demand for oil and gas’ paper presented at Natural Gas Policy Seminar Beijing, June 2000.

Hirschhausen, C and Andres, M (2000), 'Long-term electricity demand in China From quantitative to qualitative growth?', Energy policy, 28, 231-41.

Huang, J (1993), 'Industry energy use and structural change: a case study of the people's Republic of China', Energy Economics, 15(2), 131-36.

International Energy Agency (1999), 'Coal in the energy supply of China', Report of the Coal Industry Advisory Board Asia Committee, Paris.

International Monetary Fund (2003), World Economic Outlook 2003, September (http://www.imf.org/external/pubs/ft/weo/2003/02/index.htm).

Kambara, T (1992) 'The Energy Situation in China', China Quarterly, 131, 608-36.

Keii, C (2000) 'China's energy supply and demand situations and coal industry's trends today' Research Reports 162, Institute of Energy Economics, Japan. 
Li, Y (1999), 'Welcome speech' at the Sino-IEA Conference on Natural Gas Industry, Beijing, 9-10 November.

Lin, X and Polenske, K (1995) 'Input-output anatomy of China's energy use changes in the 1980s', Economic Systems Research, 7(1), 67-84.

Litterman, R.B. (1980), 'A Bayesian procedure for forecasting with vector autoregressions', Department of Economics Working Paper, Massachusetts Institute of Technology.

Litterman, R.B. (1986), 'Forecasting with bayesian vector autoregressions: Five years of experience', Journal of Business and Economic Statistics, 4(1), 25-38.

Robertson, J.C. and Tallman, E.W. (1999), 'Vector autoregressions: Forecasting and reality', Economic Review, Federal Reserve Bank of Atlanta, 4-18.

Shi, Q and Zhao, J (eds) (1999), Development Report of Chinese Industries 1999 Beijing, China ZhiGong Publishing House.

Sims, C.A. (1992), 'A nine-variable probabilistic macroeconomic forecasting model', in Stock, J.H. and Watson, M.W., Business Cycles, Indicators, and Forecasting, University of Chicago Press, Chicago.

Sims, C.A. and Zha, T.A. (1998), 'Bayesian methods for dynamic multivariate models’, International Economic Review, 39(4), 949-68.

Sinton, J and Fridley, D (2000) 'What goes up: recent trends in China's energy consumption', Energy Policy, 28, 671-87.

State Statistical Bureau (2000) China Statistical Abstract 2000 Beijing, China Statistics Press.

State Statistical Bureau (2001) China Energy Statistical Yearbook 1997-1999 Beijing, China Statistics Press.

State Statistical Bureau (2002) China Statistical Abstract 2002, Beijing, China Statistics Press.

State Statistical Bureau (2004) China Statistical Abstract 2004 Beijing, China Statistics Press.

State Statistical Bureau, (2002) A Statistical Survey of China 2002, Beijing, China Statistics Press.

State Statistical Bureau (various issues), China's Statistical Yearbook, Beijing, China Statistics Press.

Summers, P.M. (2001), 'Forecasting Australia's economic performance during the Asian crisis', International Journal of Forecasting, 17, 499-515. 
World Bank (1997), China 2020: Development Challenges in the New Century Washington DC, the World Bank.

World Bank (2002), 'Economic Indicators by Countries in the World', Washington DC: the World Bank

Zha, T. (1998), 'A dynamic multivariate model for use in formulating policy', Economic Review, Federal Reserve Bank of Atlanta, 16-29.

Zhou, F (1999), 'Role of gas in China's energy economy and long-term forecast for natural gas demand', paper presented at the Sino-IEA Conference on Natural Gas Industry, Beijing, 9-10 November 1999. 